\title{
Influência de Myrothecium roridum sobre a germinação de sementes e crescimento de plântulas de meloeiro
}

\author{
Dinara Aires Dantas ${ }^{1 *}$, José Maria da Costa $^{2}$, Salvador Barros Torres ${ }^{2}$, Elaíne Welk Lopes Pereira Nunes ${ }^{2}$ Márcia \\ Michelle de Queiroz Ambrósio², Glauber Henrique de Sousa Nunes²
}

\begin{abstract}
${ }^{1}$ Agência de Defesa Agropecuária do Estado do Ceará-ADAGRI, Av. Bezerra de Menezes, 1820 - CEP: 60.325-002. São Gerardo Fortaleza, CE, Brasil. ${ }^{2}$ Departamento de Ciências Vegetais, Universidade Federal Rural do Semi-Árido - UFERSA, Campus de Mossoró, R. Francisco Mota, 572, CEP 59625-900 - Pres. Costa e Silva, Mossoró - RN, Brasil. *Bolsista Capes.
\end{abstract}

Autor para correspondência: Glauber Henrique de Sousa Nunes (glauber@ufersa.edu.br).

Data de chegada: 13/09/2016. Aceito para publicação em: 12/06/2017.

$10.1590 / 0100-5405 / 179175$

\section{RESUMO}

Dantas, D.A.; Costa, J.M.; Torres, S.B.; Nunes, E.W.L.P.; Ambrósio, M.M.Q.; Nunes, G.H.S. Influência de Myrothecium roridum sobre a germinação de sementes e crescimento de plântulas de meloeiro. Summa Phytopathologica, v.44, n.3, p.229-235, 2018.

Muitos fungos habitantes do solo acometem a lavoura meloeira, dentre estes, destaca-se o Myrothecium roridum que prejudica várias partes da planta, inclusive a semente. O presente trabalho estudou o efeito da inoculação de $M$. roridum sobre a germinação de sementes e crescimento de plântulas de acessos/ cultivares de meloeiro, visando identificar genótipos com menor sensibilidade. $\mathrm{O}$ experimento foi realizado em delineamento inteiramente casualizados com quatro repetições em fatorial $38 \times 2$, em que o primeiro fator correspondeu aos acessos/cultivares, com 38 níveis, e o segundo, a inoculação, com dois níveis: com e sem inoculação. Foram avaliadas as características relativas à germinação (porcentagem e velocidade de emergência) e ao crescimento da plântula (altura, diâmetro do colo, peso seco da plântula e índice de área foliar). O fungo $M$. roridum afetou de forma negativa, a germinação, a velocidade de emergência e o desenvolvimento de plântulas dos acessos de meloeiro. Os acessos com menor sensibilidade ao fungo M. roridum foram A-6, A-8, A-19, A-22, A-39 e A-45.

Palavras-chave: Cucumis melo, acessos, germoplasma.

\section{ABSTRACT}

Dantas, D.A.; Costa, J.M.; Torres, S.B.; Nunes, E.W.L.P.; Ambrósio, M.M.Q.; Nunes, G.H.S.Influence of Myrothecium roridum on seed germination and seedling growth of melon plants. Summa Phytopathologica, v.44, n. 3, p.229-235, 2018.

A large number of soilborne fungi affect melon crop, among which the species Myrothecium roridum is highlighted for attacking various parts of the plant, including the seed. The present study investigated the effect of Myrothecium roridum inoculation on seed germination and seedling growth of melon accessions/cultivars in order to identify the least sensitive genotypes. The experiment was carried out in completely randomized design with four replicates in $38 \times 2$ factorial arrangement, in which the first factor corresponded to the accessions/cultivars, with 38 levels, while the second factor, inoculation, had two levels: with and without inoculation. The evaluated traits were related to germination (emergence percentage and rate) and seedling growth (height, collar diameter, seedling dry weight and leaf area index). The fungus $M$. roridum negatively affected the germination, emergence rate and seedling development of melon accessions. The accessions with least sensitivity to the fungus $M$. roridum were: A-6, A-8, A-19, A-22, A-39 and A-45.

Keywords: Cucumis melo, accessions, germoplasm.

O melão é um dos principais produtos agrícolas de exportação da região semiárida brasileira, sendo os estados do Rio Grande do Norte, no Agropolo Mossoró-Assu; e do Ceará, no Vale Jaguaribe, os principais produtores desta hortaliça. O cultivo intenso e contínuo do meloeiro tem contribuído para o aumento das enfermidades associadas aos patógenos habitantes do solo, dentre os quais está o fungo Myrothecium roridum Tode $(12,13)$. Este, foi detectado no início da década de 90 em talhões cultivados com melão amarelo no município de Mossoró, RN (18).

A espécie $M$. roridum é um parasita habitante do solo, capaz de infectar uma ampla gama de hospedeiros, inclusive cucurbitáceas de valor econômico (7). O fungo tem baixa especificidade por tecido hospedeiro podendo causar sintomas em várias partes do meloeiro. No fruto, o fungo causa rachaduras superficiais a profundas, geralmente em forma de cratera (4) sendo necessário ferimentos para que o este o colonize (17). Em plântulas, causa necrose no colo seguido de tombamento $(4,12,13)$. E, nas folhas, ocasiona a doença conhecida como mancha-de-mirotécio. Nos dois principais pólos produtores de melão do Nordeste não é comum observar sintomas nas folhas, entretanto Cabral et al. (5) verificaram que isolados coletados no Estado do Amazonas, Região Norte do Brasil, foram agressivos e causaram sintomas em folhas de cucurbitáceas, como maxixe, pepino, abóbora, moranga, melancia e melão nas condições do referido estado.

Não há registro de transmissão de $M$. roridum por sementes em meloeiro, todavia foi verificada transmissão com a espécie Myrothecium verrucaria em sementes de melão do tipo Cantaloupe nos Estados Unidos (1). Em adição, tem sido constatada a transmissão de $M$. roridum por sementes em outras cucurbitáceas como melancia $(2,3)$ e melão de São-de-Caetano, (19). Mesmo não tendo sido observada ainda sua transmissão, é frequente o isolamento de $M$. roridum em sementes de meloeiro. Há registro na literatura que esse fungo pode afetar a germinação e o crescimento de plântulas $(9,4)$. São escassos os trabalhos que abordem a sua ação sobre a germinação de sementes e 
plântulas de genótipos de meloeiro, sendo o único registro feito por Kuti et al. (8) que trabalharam com doze cultivares comerciais. Os referidos autores observaram redução na germinação e no crescimento das plântulas oriundas de sementes inoculadas com $M$. roridum, verificaram também que os cultivares diferiram quanto à sensibilidade ao fungo. Reação diferente pode existir uma vez que o meloeiro é a espécie mais polimórfica dentre as cucurbitáceas (14). No Brasil há germoplasma coletado em pequenas propriedades brasileiras que correspondem a landraces utilizadas pelos agricultores durantes muitos anos. Os acessos coletados podem ser úteis aos programas de melhoramento genético desde que caracterizados para diversos aspectos.

Assim sendo, considerando a existência de acessos da coleção ativa de germoplasma da Universidade Federal Rural do Semi-Árido (UFERSA) que precisam de caracterização e maiores informações, o presente trabalho teve como objetivo avaliar o efeito da inoculação de M. roridum sobre a germinação de sementes e crescimento de plântulas de acessos/cultivares de meloeiro.

\section{MATERIAL E MÉTODOS}

O experimento foi conduzido na UFERSA utilizando 33 acessos de meloeiro pertencentes ao Banco de Germoplasma desta Instituição (A-2, A-3, A-4, A-5, A-6, A-7, A-8, A-9, A-12, A-13, A-14, A-15, A-16, A-17, A-18, A-19, A-22, A-23, A-25, A-26, A-27, A-28, A-30, A-31, A-33, A-34, A-36, A-37, A-39, A-41, A-43, A-44 e A-45), coletados na região Nordeste do Brasil, bem como os híbridos do tipo amarelo 'Mabel', 'Natal', 'Amaral', 'Mandacaru' e o híbrido do tipo pele de sapo 'Sancho'.

O isolado CMM-639 foi obtido de uma planta de meloeiro cultivado em Mossoró, RN e conservado na coleção de Culturas de Fungos Fitopatogênicos "Professora Maria Menezes" - CMM, da Universidade Federal Rural de Pernambuco - UFRPE, Recife, PE. A multiplicação do fungo foi realizada em meio de cultura Beterraba-Dextrose-Ágar (BTDA). $\mathrm{O}$ inóculo fúngico foi incubado por 15 dias a $25^{\circ} \mathrm{C}$, em estufas tipo Biochemistry Oxigen Damand (B.O.D.), sob alternância de luminosidade de $12 \mathrm{~h}$ (claro/escuro).

A suspensão de esporos fúngicos foi preparada com a adição de $10 \mathrm{~mL}$ de água destilada a uma placa de Petri contendo uma colônia de sete dias de $M$. roridum e, com uma uma escova dental de cerdas macias, raspou-se suavemente a superfície da colônia para facilitar a liberação dos esporos; em seguida, essa suspensão foi filtrada através de uma camada dupla de gaze sobre um funil acoplado a um Erlemeyer, sendo a suspensão ajustada para a concentração de 1 x $10^{6}$ conídios/ mL, na câmara de Neubauer (8).

Os acessos e cultivares foram divididos em duas subamostras de 80 sementes que foram colocadas em placas de Petri. A primeira subamostra correspondeu ao tratamento inoculado, enquanto a segunda, ao tratamento não inoculado, considerado como testemunha. Antes da inoculação, as sementes foram desinfestadas em hipoclorito de sódio $(1,5 \%)$ por dois minutos, lavadas em água destilada esterilizada e colocadas para secar em condições de laboratório $\left(27 \pm 2^{\circ} \mathrm{C}\right.$; UR $67 \pm 4 \%$ ). Para inoculação, as sementes contidas em placas de Petri foram submersas em $15 \mathrm{~mL}$ da suspensão de esporos por oito horas. No tratamento não inoculado (testemunha), as sementes foram submersas em $15 \mathrm{~mL}$ de água destilada esterilizada (8). Em seguida, as sementes foram semeadas em substrato contido em bandejas de polietileno de 200 células previamente higienizadas e desinfestadas em solução de hipoclorito de sódio, na proporção de 3:1 (hipoclorito:água), durante
30 minutos e lavadas em água potável. Posteriormente, foram postas para secar em temperatura ambiente. O substrato utilizado foi o Vivatto Slim $^{\circledR}$ (composto por moinha de carvão vegetal, casca de pinus e turfa), autoclavado a $120^{\circ} \mathrm{C}$, por duas horas em dois dias consecutivos.

As bandejas foram transferidas para casa de vegetação onde foi realizado o acompanhamento diário da germinação das sementes para determinação do percentual de germinação (PG) e do índice de velocidade de germinação (IVG) até 30 dias após a semeadura. O PG de plântulas normais foi obtida pela contagem do número final de plântulas germinadas. O IVG foi determinado conforme metodologia de Maguire (10).

As bandejas foram irrigadas, pela manhã e no final da tarde, por meio de um sistema de microaspersão com vazão média de $35 \mathrm{~L} / \mathrm{h}$. Transcorridos 30 dias da semeadura, retirou-se uma amostra de forma aleatória, composta por dez indivíduos de cada acesso e cultivar em cada repetição, nos tratamentos inoculado e não inoculado. As plântulas foram cortadas rente ao substrato, para aferição das variáveis a serem avaliadas.

As variáveis avaliadas foram às seguintes: a) altura da plântula: medida da base do colo ao início da inserção dos cotilédones por meio de uma régua milimétrica; b) diâmetro do colo: a medição realizada na base do colo com auxílio de um paquímetro digital; c) índice de área foliar: obtido pela análise de imagem digital processado pelo programa $\left(\right.$ Sigmascan $\left.^{\circledR}\right)$; d) peso seco: pesagem efetuada em balança de precisão $(0,001 \mathrm{~g})$ e, posteriormente, colocadas em estufa de circulação forçada a $65^{\circ} \mathrm{C}$ por 48 horas para obtenção do peso seco.

$\mathrm{O}$ delineamento experimental utilizado foi o inteiramente casualizado com quatro repetições, em esquema fatoriasl 38 x 2, em que o primeiro fator correspondeu aos acessos e cultivares, com 38 níveis; e o segundo fator a inoculação, com dois níveis: inoculado e não inoculado. A unidade experimental foi constituída de 20 sementes.

Realizou-se a análise de variância e o teste F de Snedecor para todas as características avaliadas. As médias das populações inoculadas e não inoculadas foram comparadas pelo teste $t$ de Student. As médias dos acessos e híbridos foram agrupadas pelo método de Scott-Knott (16). Em todas as análises foi utilizado o nível nominal de significância de $5 \%$ de probabilidade $(\alpha=0,05)$.

Para todas as características avaliadas foram estimadas as reduções em relação à testemunha (semente não inoculada) conforme a metodologia utilizada por Sultana \& Ghaffar (19). As observações relativas às reduções das características de germinação e de crescimento avaliadas foram padronizadas por parcela, visando torná-las diretamente comparáveis, conforme metodologia proposta por Mendes et al. (11).

A variável padronizada $Z_{\mathrm{ij}}$ foi obtida pelo seguinte estimador:, em que $Z_{\mathrm{ij}}$ é o valor da variável padronizada do material $\mathrm{i}$ (acesso/cultivar) $(i=1,2, \ldots, 38)$ na repetição $j(j=1,2,4)$; $y_{i j}$ é a observação da variável do material i na repetição j; é a média geral da variável dos 38 materiais na repetição j e $\mathrm{s}_{\mathrm{j}}$ é o desvio-padrão fenotípico da variável da repetição j.

Como a variável $Z_{\mathrm{ij}}$ assume valores negativos e positivos, foi somado o valor três às suas estimativas, para tornar impossível a ocorrência de valores negativos (11). Neste caso, a média populacional, em vez de zero, passou a ser três. Após a padronização das variáveis, foi obtido o somatório por parcela, que correspondeu ao somatório das duas variáveis padronizadas para germinação (índice $Z_{\mathrm{g}}$ ). Da mesma maneira, foi obtido o índice $Z_{c}$ pelo somatório das quatro variáveis relacionadas ao crescimento das plântulas. Os índices $Z_{\mathrm{g}}$ e $Z_{c}$ que apresentaram os maiores valores corresponderam ao índice desfavorável e os menores valores, ao índice favorável uma vez que foram construídos com base nas reduções em relação à média. Assim, 
quanto maior a redução maior o valor de Z. Os valores dos índices foram utilizados como coordenadas em um gráfico bi-dimensional para facilitar a visualização e a identificação dos materiais mais e menos sensíveis ao fungo. $\mathrm{O}$ índice $\mathrm{Z}_{\mathrm{g}}$ correspondeu à abcissa enquanto que o índice $Z_{c}$ à ordenada.

O processamento das análises foi realizado utilizando o Software $\mathrm{R}$ (15). Foi utilizado o programa Statistica ${ }^{\circledR}$ Versão 7.0 para a construção do gráfico bi-dimensional.

\section{RESULTADOS E DISCUSSÃO}

$\mathrm{Na}$ análise de variância, verificou-se efeitos significativos para as fontes de variação, inoculação, acessos e interação entre estes fatores $(\mathrm{p}<0,05)$ em todas as características avaliadas (Tabela 1). Ressalta-se que a interação constatada entre inoculação e acessos/ cultivares foi praticamente toda de natureza simples. A interação do tipo simples é devida as variações nas magnitudes das diferenças dos acessos/cultivares nas avaliações feitas em sementes e plântulas com ou sem inoculação. A presença da interação do tipo simples facilita o trabalho de seleção dos materiais avaliados uma vez que nesta situação a ordenação dos acessos/cultivares não é alterada independente da presença do fungo.

Em todas as características verificou-se que as médias obtidas na presença do fungo foram inferiores àquelas obtidas na ausência do mesmo (Tabela 2). Este fato indica que a presença do M. roridum na semente prejudica a germinação e o crescimento de plântulas de meloeiro. Ressalta-se que o efeito da inoculação nas sementes, mesmo sendo significativo, foi reduzido para todas as características avaliadas, sendo a maior diferença, em termos percentuais, constatada para o peso seco (Tabela 1). São raras as informações sobre o efeito do fungo $M$. roridum sobre a germinação e crescimento de plântulas de meloeiro. O único relato encontrado na literatura foi publicado por Kuti et al. (8) ao avaliar doze cultivares comerciais de meloeiro. Estes autores verificaram que as plântulas oriundas de sementes inoculadas com $M$. roridum apresentaram redução na germinação, embora com estimativas superiores àquelas do presente trabalho. As diferenças na influência do fungo nos dois estudos podem ser explicadas pelo grupo de cultivares estudado, isolado do patógeno e condições ambientais, uma vez que a metodologia utilizada nos dois ensaios foi a mesma.

A verificação da influência do fungo sobre a germinação do meloeiro no presente trabalho ratifica o comentário feito por Bruton (2004), sobre a ação nociva de $M$. roridum na germinação de cucurbitáceas. Assim sendo, os resultados observados neste trabalho para germinação de sementes de meloeiro são relevantes, em especial, para os pequenos produtores desta cucurbitácea dos estados brasileiros que utilizam sementes landraces em estações de cultivo subsequentes a colheita (6). Por outro lado, reforça a necessidade do tratamento de sementes com fungicidas para o controle do patógeno estudado $(1,19)$.

Concernente às características relacionadas à germinação, verificouse heterogeneidade entre os acessos/cultivares conforme a metodologia de Scott-Knott (Tabelas 2). Para o PG houve a formação de cinco grupos. $\mathrm{O}$ primeiro grupo, composto por 25 materiais, correspondeu àqueles com maior PG, com valores variando de 92,5 a $100 \%$, perfazendo uma reduzida amplitude de 7,5\%. O segundo grupo foi formado por cinco materiais com valores variando de 75 a $87,50 \%$. O terceiro grupo foi composto pelos acessos A-23 e A-37 com germinações intermediárias e consideradas inadequadas para a cultura. Nos grupos quatro e cinco, cada um composto por três materiais, as porcentagens de germinação foram muito reduzidas com valores menores ou iguais a $50 \%$. Estes dois grupos contemplaram os híbridos 'Amaral', 'Sancho' e 'Mabel', cultivados no Agropólo Mossoró-Assu. A correlação entre as médias dos acessos/cultivares e as reduções em relação à testemunha (sementes não inoculadas) foi altamente significativa e negativa (Tabela 2), indicando que quanto maior a germinação menor a redução. A estimativa e o sinal do coeficiente de correlação confirmam a influência negativa do fungo sobre a germinação dos materiais avaliados. Kuti et al. (8) observaram diferenças entre os cultivares avaliados com uma amplitude da redução da germinação em relação à testemunha (sementes não inoculadas) de $70,2 \%$ com valores máximos e mínimos, 27,3 e 97,5\%, respectivamente.

Em relação ao IVG constatou-se maior discriminação entre os materiais, com a formação de oito grupos. Destaque para os acessos do primeiro grupo com maiores índices, variando de 2,47 para (A-9) e 2,81 para (A-18) (Tabela 2). Os materiais com as menores estimativas estavam no oitavo grupo, com valores variando de 0,10 ('Mabel') a 0,22 (A-4). Novamente, menores valores médios indicam maiores reduções em relação à testemunha, fato comprovado pela correlação negativa $\mathrm{e}$ significativa (Tabela 2).

Observou-se variação para todas as características relacionadas ao crescimento das plântulas (Tabela 3). Para a altura da plântula, constatou-se a formação de quatro grupos. Os acessos A-13 e A-22 juntamente com o híbrido 'Natal' formaram o primeiro grupo, com

Tabela 1. Valores de F da análise de variância sobre seis características avaliadas em acessos/cultivares de meloeiro com sementes inoculadas e não inoculadas com $M$. roridum.

\begin{tabular}{|c|c|c|c|c|c|c|}
\hline \multirow[t]{2}{*}{ FV } & \multicolumn{4}{|c|}{ Características } & \multirow[b]{2}{*}{ PS } & \multirow[b]{2}{*}{ IAF } \\
\hline & PGE & IVE & ALT & DIAM & & \\
\hline & $(\%)$ & & $(\mathrm{cm})$ & $(\mathrm{cm})$ & (g) & \\
\hline Acessos & $39,29^{* *}$ & $62,20^{* * *}$ & $101,61^{* *}$ & $24,96^{* *}$ & $8,59^{* *}$ & $30,09^{* *}$ \\
\hline $\mathrm{I} \times \mathrm{A}$ & $6,37^{* *}$ & $18,84^{* *}$ & $9,11^{* *}$ & $10,05^{* *}$ & $10,28^{* *}$ & $6,76^{* *}$ \\
\hline Não inoculado & $96,09 \mathrm{a}$ & $2,22 \mathrm{a}$ & $4,52^{\mathrm{a}}$ & $2,73 \mathrm{a}$ & $0,56 \mathrm{a}$ & $4,70 \mathrm{a}$ \\
\hline Valor de $\mathrm{t}$ & $6,59^{* * *}$ & $3,12^{* *}$ & $7,56^{* *}$ & $4,22^{* *}$ & $7,97^{* *}$ & $4,34^{* *}$ \\
\hline prob & 0,001 & 0,002 & 0,001 & 0,001 & 0,005 & 0,010 \\
\hline
\end{tabular}

***: significativo a 5 e 1\% de probabilidade pelo teste F de Snedecor. PGE: percentual de germinação, em \%; IVE: índice de velocidade de emergência; ALT: altura de plântula, em cm; diâmetro do colo, em cm; PS: peso da matéria seca da plântula, em g; IAF: índice de área foliar. 
Tabela 2. Média da porcentagem de germinação (PGE, em \%) e índice de velocidade de emergência (IVE) obtidas em sementes de acessos/ cultivares de meloeiro inoculadas com $M$. roridum e suas respectivas reduções (RED) em relação à testemunha (sementes não inoculadas).

\begin{tabular}{|c|c|c|c|c|c|c|}
\hline \multirow[t]{2}{*}{ Acesso/Cultivar } & \multicolumn{6}{|c|}{ Médias/Características } \\
\hline & PGE & & RED & IVE & & RED \\
\hline A-2 & 92,50 & A & 7,50 & 2,23 & B & 21,33 \\
\hline A-3 & 92,50 & A & 7,50 & 1,86 & $\mathrm{C}$ & 31,60 \\
\hline A-4 & 17,50 & E & 59,17 & 0,22 & G & 44,38 \\
\hline A-5 & 100,00 & A & 0,00 & 2,58 & A & 7,90 \\
\hline A-6 & 95,00 & A & 5,00 & 2,10 & B & 9,60 \\
\hline A-7 & 97,50 & A & 2,50 & 2,31 & B & 5,55 \\
\hline A-8 & 100,00 & A & 0,00 & 2,34 & B & 4,28 \\
\hline A-9 & 100,00 & A & 0,00 & 2,47 & A & 2,94 \\
\hline A-12 & 75,00 & B & 21,11 & 1,36 & $\mathrm{D}$ & 11,22 \\
\hline A-13 & 100,00 & A & 0,00 & 1,79 & $\mathrm{C}$ & 28,43 \\
\hline A-14 & 100,00 & A & 0,00 & 2,65 & A & 7,91 \\
\hline A-15 & 95,00 & A & 5,00 & 2,38 & B & 6,22 \\
\hline A-16 & 100,00 & A & 0,00 & 1,57 & D & 45,86 \\
\hline A-17 & 95,00 & A & 5,00 & 1,86 & $\mathrm{C}$ & 10,81 \\
\hline A-18 & 97,50 & A & 2,50 & 2,81 & A & 8,49 \\
\hline A-19 & 95,00 & A & 5,00 & 2,19 & B & 12,34 \\
\hline A-22 & 100,00 & A & 0,00 & 2,56 & A & 12,47 \\
\hline A-23 & 60,00 & $\mathrm{C}$ & 31,59 & 0,71 & F & 62,91 \\
\hline A- 25 & 92,50 & A & 5,28 & 2,18 & B & 9,81 \\
\hline A-26 & 100,00 & A & 0,00 & 2,39 & B & 5,88 \\
\hline A-27 & 95,00 & A & 5,00 & 1,13 & $\mathrm{E}$ & 22,55 \\
\hline A-28 & 87,50 & B & 10,00 & 1,59 & D & 16,19 \\
\hline A-30 & 95,00 & A & 5,00 & 1,81 & $\mathrm{C}$ & 20,90 \\
\hline A-31 & 42,50 & D & 48,93 & 0,36 & F & 37,15 \\
\hline A-33 & 100,00 & A & 0,00 & 2,18 & B & 11,14 \\
\hline A-34 & 87,50 & B & 5,28 & 1,69 & $\mathrm{C}$ & 21,68 \\
\hline A-36 & 90,00 & A & 10,00 & 1,46 & $\mathrm{D}$ & 20,64 \\
\hline A-37 & 62,50 & $\mathrm{C}$ & 33,33 & 0,62 & F & 59,94 \\
\hline A-39 & 92,50 & A & 7,50 & 1,61 & D & 9,03 \\
\hline A-41 & 97,50 & A & 2,50 & 2,29 & B & 6,30 \\
\hline A-43 & 82,50 & B & 17,50 & 1,55 & $\mathrm{D}$ & 17,45 \\
\hline A-44 & 50,00 & D & 38,54 & 0,87 & $\mathrm{E}$ & 52,71 \\
\hline A-45 & 95,00 & A & 5,00 & 2,27 & B & 9,71 \\
\hline 'Natal & 77,50 & B & 17,50 & 0,58 & F & 72,43 \\
\hline 'Amaral' & 42,50 & D & 56,11 & 0,66 & F & 36,86 \\
\hline 'Sancho' & 12,50 & E & 72,50 & 0,18 & G & 60,32 \\
\hline 'Mandacaru' & 97,50 & A & 2,50 & 2,42 & B & 13,04 \\
\hline 'Mabel' & 5,00 & E & 87,50 & 0,10 & G & 77,27 \\
\hline$r^{1}$ & \multicolumn{3}{|c|}{$-0,98(\mathrm{p}<0,01)$} & \multicolumn{3}{|c|}{$-0,86(\mathrm{p}<0,01)$} \\
\hline
\end{tabular}

Médias seguidas pela mesma letra pertencem ao mesmo grupo conforme método de Scott-Knott $(\mathrm{p}<0,05) .{ }^{1}$ Correlação de Spearman entre a média da característica avaliada na presença do fungo e a redução em relação à testemunha (sementes não inoculadas). as maiores médias, próximas ou superiores a $6,0 \mathrm{~cm}$, enquanto que no grupo quatro, os acessos A-2, A-9 e A-25 bem como os híbridos 'Sancho' e 'Mabel' apresentaram os menores valores médios, com estimativas próximas ou inferiores a $1,0 \mathrm{~cm}$.

Com relação ao diâmetro da plântula, observou-se a formação de três grupos (Tabela 3). O primeiro grupo foi composto pela maioria dos materiais e apresentou as maiores médias, com valores variando de 2,26 (A-23) a 3,0 cm (A-45). O segundo grupo foi constituído por 14 materiais, com médias de 1,39 (A-16) a 2,11 cm (A-6). No terceiro grupo foram locados os materiais A-2, A-9, A-25, 'Sancho' e 'Mabel', todos com valores de diâmetro inferiores a $1,0 \mathrm{~cm}$.

Com relação ao peso seco da plântula, o primeiro grupo foi composto por 16 materiais com as maiores estimativas, em uma variação de 0,38 ('Amaral') a 0,70 (A-8). O segundo e o terceiro grupos foram formados por onze materiais, sendo o terceiro grupo composto pelos materiais de menor peso seco. Mais uma vez os materiais A-2, A-9, A-25, 'Sancho' e 'Mabel' apresentaram as menores médias. Kuti et al. (8) relataram pequenas reduções para o peso seco da raiz quando comparada à testemunha, embora três cultivares tenham tido reduções superiores a $40 \%$. No presente trabalho, as reduções no peso seco da plântula variaram de 11,02 (A-45) a 93,42\% (A-9).

Para o índice de área foliar os acessos/cultivares foram discriminados em quatro grupos. No primeiro grupo foram locados seis acessos e os híbridos 'Natal' e 'Amaral' com valores superiores a 4,0 (Tabela 3). No quarto grupo, de materiais com menores estimativas, foram locados os acessos A-2, A-9, A-25 e os híbridos 'Sancho' e 'Mabel', assim como foi verificado para as demais características relacionadas ao desenvolvimento da plântula.

Considerando as quatro características relacionadas ao crescimento ao mesmo tempo, foi possível constatar que os acessos A-13 e A-22, bem como o híbrido 'Natal' sempre foram discriminados no primeiro grupo (maiores estimativas) (Tabela 3). Por outro lado, os acessos A-2, A-9, A-25 e os híbridos 'Mabel' e 'Sancho' possuíram os menores valores, estando sempre agrupados entre os materiais com as menores estimativas (Tabela 3).

Verificou-se associação elevada e negativa entre as estimativas das médias das quatro características utilizadas para avaliar o crescimento das plântulas dos acessos/cultivares e as reduções em relação à testemunha (plântulas de sementes não inoculadas) (Tabela 3). Estes resultados eram esperados uma vez que quanto maior a média na plântula oriunda de sementes inoculadas em relação à testemunha, menor é a redução decorrente da ação do fungo.

A variação entre os acessos e cultivares tanto para as características de germinação como de crescimento da plântula é provavelmente devida a duas fontes (inoculado e não inoculado). A primeira é a própria constituição genética dos mesmos que proporciona reações distintas dos genótipos frente à inoculação com o fungo. Outra fonte de variação é a própria condição da semente utilizada no estudo. As sementes dos acessos variam em vigor e isso pode, até certo ponto, confundir os resultados. Todavia, a presença do tratamento testemunha (sementes não inoculadas) auxilia na interpretação dos resultados e permitem maior segurança na discriminação dos materiais menos sensíveis pela estimativa da redução. Assim sendo, considerando as estimativas de redução para as duas categorias de variáveis utilizadas (germinação e crescimento) foi possível criar dois índices. O primeiro índice, denotado por $Z_{g}$, está associado às reduções observadas nas características vinculadas à germinação das sementes, enquanto que o segundo índice, $Z_{c}$, está vinculado às reduções nas características de crescimento das plântulas. Como foram criados a partir das reduções 
Tabela 3. Média da altura (ALT, em cm), diâmetro (DIAM, em cm), peso seco (PSE, em g) e índice de área foliar (IAF, em \%) de plântulas oriundas de sementes de acessos/cultivares de meloeiro inoculadas com $M$. roridum e suas respectivas reduções (RED) em relação à testemunha (sementes não inoculadas).

\begin{tabular}{|c|c|c|c|c|c|c|c|c|c|c|c|c|}
\hline \multirow[t]{2}{*}{ Acesso/Cultivar } & \multicolumn{12}{|c|}{ Médias/Características } \\
\hline & ALT & & RED & DIAM & & RED & PSE & & RED & IAF & & RED \\
\hline A-2 & 0,64 & d & 91,32 & 0,72 & $\mathrm{c}$ & 76,87 & 0,04 & $\mathrm{c}$ & 92,76 & 0,71 & $\mathrm{~d}$ & 91,43 \\
\hline A-3 & 2,45 & $\mathrm{c}$ & 49,60 & 1,62 & $\mathrm{~b}$ & 31,52 & 0,07 & $\mathrm{c}$ & 87,54 & 2,54 & $\mathrm{c}$ & 41,65 \\
\hline A-4 & 1,84 & $\mathrm{c}$ & 36,34 & 1,49 & $\mathrm{~b}$ & 33,40 & 0,08 & $\mathrm{c}$ & 63,00 & 1,99 & $\mathrm{c}$ & 40,71 \\
\hline A-5 & 3,03 & $\mathrm{c}$ & 17,01 & 2,65 & $\mathrm{a}$ & 18,65 & 0,42 & $\mathrm{a}$ & 30,30 & 3,90 & $\mathrm{~b}$ & 22,35 \\
\hline A-6 & 2,73 & $\mathrm{c}$ & 17,58 & 2,11 & $\mathrm{~b}$ & 15,32 & 0,32 & $\mathrm{~b}$ & 43,04 & 2,96 & $\mathrm{~b}$ & 17,57 \\
\hline A-7 & 4,20 & $\mathrm{~b}$ & 18,00 & 2,65 & a & 3,29 & 0,42 & $\mathrm{a}$ & 31,21 & 4,06 & b & 25,51 \\
\hline A- 8 & 4,22 & b & 22,05 & 2,88 & $\mathrm{a}$ & 10,26 & 0,70 & $\mathrm{a}$ & 16,79 & 4,62 & $\mathrm{a}$ & 24,76 \\
\hline A-9 & 0,71 & $d$ & 85,25 & 0,55 & $\mathrm{c}$ & 83,19 & 0,06 & $\mathrm{c}$ & 93,42 & 0,75 & $d$ & 88,20 \\
\hline A-12 & 2,82 & $\mathrm{c}$ & 19,61 & 1,61 & b & 34,01 & 0,20 & $\mathrm{c}$ & 54,87 & 2,16 & $\mathrm{c}$ & 30,87 \\
\hline A-13 & 6,58 & $\mathrm{a}$ & 31,99 & 2,44 & $\mathrm{a}$ & 10,32 & 0,40 & $\mathrm{a}$ & 37,00 & 5,52 & $\mathrm{a}$ & 22,85 \\
\hline A-14 & 3,57 & $\mathrm{~b}$ & 21,07 & 2,40 & $\mathrm{a}$ & 9,66 & 0,41 & $\mathrm{a}$ & 34,03 & 3,39 & b & 39,12 \\
\hline A-15 & 2,79 & $\mathrm{c}$ & 14,28 & 2,07 & $\mathrm{~b}$ & 9,62 & 0,28 & $\mathrm{~b}$ & 25,13 & 2,77 & b & 58,05 \\
\hline A-16 & 4,10 & $\mathrm{~b}$ & 36,87 & 1,39 & $\mathrm{~b}$ & 37,91 & 0,26 & $\mathrm{~b}$ & 18,81 & 3,95 & b & 34,92 \\
\hline A-17 & 3,65 & $\mathrm{~b}$ & 14,61 & 1,56 & $\mathrm{~b}$ & 41,75 & 0,25 & $\mathrm{~b}$ & 44,78 & 2,14 & $\mathrm{c}$ & 34,03 \\
\hline A-18 & 4,55 & b & 16,40 & 1,90 & b & 39,04 & 0,39 & $\mathrm{a}$ & 39,82 & 3,39 & b & 31,46 \\
\hline A-19 & 3,86 & $\mathrm{~b}$ & 18,41 & 2,66 & a & 6,33 & 0,47 & $\mathrm{a}$ & 19,80 & 3,82 & b & 14,99 \\
\hline A-22 & 6,53 & $\mathrm{a}$ & 14,37 & 2,64 & $\mathrm{a}$ & 5,27 & 0,47 & $\mathrm{a}$ & 22,02 & 5,32 & $\mathrm{a}$ & 15,63 \\
\hline A-23 & 2,44 & $\mathrm{c}$ & 21,25 & 2,17 & a & 21,28 & 0,27 & b & 36,47 & 3,07 & b & 30,00 \\
\hline A- 25 & 0,79 & $d$ & 91,31 & 0,68 & $\mathrm{c}$ & 77,85 & 0,11 & $\mathrm{c}$ & 80,93 & 1,05 & $d$ & 84,25 \\
\hline A-26 & 1,91 & $\mathrm{c}$ & 35,81 & 1,65 & $\mathrm{~b}$ & 30,96 & 0,10 & $\mathrm{c}$ & 69,55 & 2,14 & $\mathrm{c}$ & 30,79 \\
\hline A-27 & 2,52 & $\mathrm{c}$ & 21,22 & 2,23 & $\mathrm{a}$ & 8,36 & 0,29 & $\mathrm{~b}$ & 31,09 & 3,05 & b & 15,26 \\
\hline A-28 & 3,28 & $\mathrm{c}$ & 13,51 & 2,50 & $\mathrm{a}$ & 10,06 & 0,33 & $\mathrm{~b}$ & 37,62 & 3,31 & b & 10,49 \\
\hline A-30 & 2,79 & $\mathrm{c}$ & 26,31 & 2,36 & $\mathrm{a}$ & 9,73 & 0,27 & $\mathrm{~b}$ & 45,76 & 3,20 & b & 16,96 \\
\hline A-31 & 2,49 & $\mathrm{c}$ & 19,58 & 1,94 & $\mathrm{~b}$ & 15,99 & 0,06 & $\mathrm{c}$ & 76,40 & 2,10 & $\mathrm{c}$ & 23,69 \\
\hline A-33 & 2,99 & $\mathrm{c}$ & 22,49 & 1,67 & $\mathrm{~b}$ & 29,28 & 0,11 & $\mathrm{c}$ & 67,67 & 2,71 & b & 34,81 \\
\hline A-34 & 2,84 & $\mathrm{c}$ & 19,15 & 1,64 & $\mathrm{~b}$ & 44,96 & 0,27 & $\mathrm{~b}$ & 55,10 & 2,30 & $\mathrm{c}$ & 53,55 \\
\hline A-36 & 2,68 & $\mathrm{c}$ & 31,78 & 2,26 & $\mathrm{a}$ & 23,06 & 0,41 & $\mathrm{a}$ & 31,36 & 2,80 & $\mathrm{~b}$ & 37,46 \\
\hline A-37 & 2,89 & $\mathrm{c}$ & 20,44 & 2,53 & a & 17,71 & 0,52 & $\mathrm{a}$ & 12,19 & 3,81 & b & 15,35 \\
\hline A-39 & 2,41 & $\mathrm{c}$ & 18,24 & 2,46 & $\mathrm{a}$ & 9,97 & 0,33 & $\mathrm{~b}$ & 17,95 & 3,03 & b & 20,87 \\
\hline A- -41 & 3,95 & $\mathrm{~b}$ & 20,87 & 2,68 & $\mathrm{a}$ & 8,54 & 0,43 & $\mathrm{a}$ & 42,74 & 3,11 & $\mathrm{~b}$ & 31,02 \\
\hline A- 43 & 4,85 & b & 11,77 & 2,06 & $\mathrm{~b}$ & 15,82 & 0,35 & $\mathrm{~b}$ & 19,89 & 3,76 & b & 21,93 \\
\hline A-44 & 2,69 & $\mathrm{c}$ & 16,68 & 2,58 & a & 17,75 & 0,52 & $\mathrm{a}$ & 15,21 & 4,47 & $\mathrm{a}$ & 9,66 \\
\hline A- 45 & 3,14 & $\mathrm{c}$ & 27,54 & 3,00 & $\mathrm{a}$ & 8,36 & 0,54 & $\mathrm{a}$ & 11,02 & 4,27 & a & 14,71 \\
\hline 'Natal & 5,90 & $\mathrm{a}$ & 12,77 & 2,59 & a & 3,58 & 0,52 & $\mathrm{a}$ & 21,35 & 6,20 & $\mathrm{a}$ & 10,36 \\
\hline 'Amaral' & 3,89 & $\mathrm{~b}$ & 19,50 & 2,36 & $\mathrm{a}$ & 15,42 & 0,38 & $\mathrm{a}$ & 35,75 & 4,16 & a & 11,89 \\
\hline 'Sancho' & 0,93 & d & 85,89 & 0,64 & $\mathrm{c}$ & 79,12 & 0,08 & $\mathrm{c}$ & 90,41 & 0,77 & d & 75,76 \\
\hline 'Mandacaru' & 3,52 & $\mathrm{~b}$ & 32,25 & 1,89 & $\mathrm{~b}$ & 29,55 & 0,43 & $\mathrm{a}$ & 29,14 & 3,39 & b & 37,26 \\
\hline 'Mabel' & 0,83 & d & 89,57 & 0,62 & $\mathrm{c}$ & 81,76 & 0,06 & $\mathrm{c}$ & 92,12 & 1,18 & d & 69,54 \\
\hline
\end{tabular}

Médias seguidas pela mesma letra pertencem ao mesmo grupo conforme método de Scott-Knott $(\mathrm{p}<0,05)$. ${ }^{1}$ Correlação de Spearman entre a média da característica avaliada na presença do fungo e a redução em relação à testemunha (sementes não inoculadas). 
observadas era óbvio que quanto maior o valor do índice maior é a redução no material.

A construção de um gráfico bidimensional tendo como coordenadas os valores dos índices $\mathrm{Z}$ permitiu uma melhor visualização do comportamento dos acessos/cultivares, auxiliando na identificação dos materiais mais e menos sensíveis à ação do fungo inoculado nas sementes. Nesse sentido, observando o gráfico foi possível identificar quatro grupos de materiais (Figura 1).

O primeiro grupo foi formado por materiais com menores reduções na germinação (menor estimativa de $Z_{g}$ ) e elevadas reduções no crescimento da plântula causado pelo fungo (maior estimativa de $Z_{c}$ ) (Figura 1). Os acessos A-2, A-9 e A-25 foram alocados neste grupo por possuírem excelente germinação mesmo na presença do fungo ( $>$ 92\%) (Tabela 2) e elevada redução nas características relacionadas ao crescimento da plântula. Estes três materiais sempre estiveram entre os piores para todas as características de crescimento (Tabela 3). Para os acessos A-2 e A-9 observou-se muitas plântulas com sintomas de cancro de mirotécio, inclusive com morte de algumas plantas. Fato semelhante foi observado em plântulas de melancia obtidas de sementes inoculadas com Myrothecium roridum (2, 3) e Myrothecium verrucaria (2, 3). Sultana e Ghaffar (19) constataram sintomas nas folhas, apodrecimento das raízes e morte das plântulas de Momordica charantia oriundas de sementes inoculadas.

No segundo grupo foram alocados os materiais com maiores reduções na germinação (maior estimativa de $Z_{\mathrm{g}}$ ) e elevadas reduções no crescimento da plântula causado pelo fungo (maior estimativa de $Z_{c}$ ). Apenas os híbridos 'Sancho' e 'Mabel' apresentaram esse comportamento, sendo, portanto, os mais sensíveis ao fungo (Figura 1).
Nos referidos materiais a maioria das plântulas apresentaram sintomas de cancro de mirotécio no colo com posterior morte, ratificando a maior sensibilidade dos dois híbridos citados.

No terceiro grupo, foram discriminados materiais com maiores reduções na germinação (maior estimativa de $Z_{\mathrm{g}}$ ) e menores reduções no crescimento da plântula (menor estimativa de $Z_{c}$ ) (Figura 1). Todos os materiais deste grupo possuem baixa ou mediana porcentagem de germinação e reduzido índice de velocidade de emergência (Tabela 2).

$\mathrm{O}$ grupo quatro foi formado pela maioria dos materiais avaliados no presente estudo. Neste grupo foram alocados os materiais que combinam menores valores dos índices $Z$ de germinação $\left(Z_{g}\right)$ e crescimento $\left(Z_{c}\right)$. Todavia, pode-se observar uma pequena heterogeneidade dentro deste grupo, devido principalmente a maior variação nos valores do índice $\mathrm{Z}$ de crescimento (Figura 1). Em razão disso, foi possível apontar um subgrupo formado pelos acessos A-6, A-8, A-19, A-22, A-39 e A-45. Os referidos acessos podem ser considerados, segundo os dois índices utilizados $\left(Z_{\mathrm{g}}\right.$ e $\left.Z_{\mathrm{c}}\right)$, os menos sensíveis ao fungo. Ressaltase que os índices $Z_{\mathrm{g}}$ e $Z_{\mathrm{c}}$ são combinações lineares de duas ou mais características. Assim sendo, poderia ter o conveniente de que como a identificação dos materiais menos sensíveis ao ataque do fungo é feita em índices que foram construídos pela combinação linear de duas ou mais características, muitos materiais considerados como de maior sensibilidade poderiam ter elevadas reduções em relação à testemunha (semente não inoculada) em uma ou mais características, devido à ação fúngica. Entretanto, tal fato não ocorreu, evidenciando que a metodologia foi adequada para discriminar o conjunto de acessos/ cultivares avaliado quanto à sensibilidade ao fungo M. roridum.

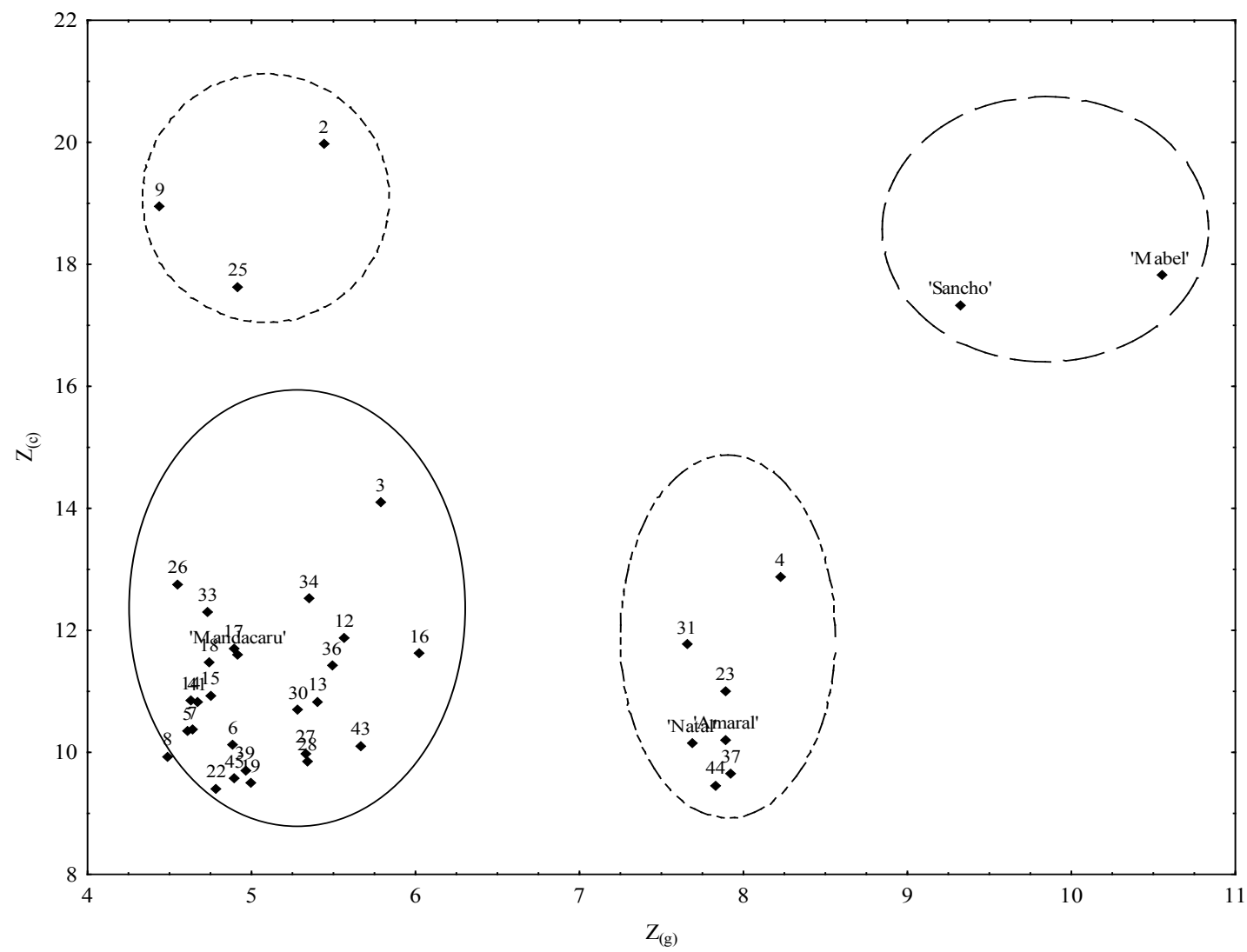

Figura 1. Dispersão de acessos/cultivares de meloeiro em função dos índice $Z$ de germinação $\left(Z_{g}\right)$ e crescimento $\left(Z_{c}\right)$. 
- O fungo M. roridum afeta de forma negativa a germinação, a velocidade de emergência e o desenvolvimento de plântulas de acessos de meloeiro.

- Os acessos com menor sensibilidade ao fungo M. roridum são: A-6, A-8, A-19, A-22, A-39 e A-45.

\section{AGRADECIMENTOS}

À Coordenação de Aperfeiçoamento de Pessoal de Nível Superior (CAPES) pela bolsa de Doutorado concedida o primeiro autor (554466/2009-0) e financiamento da pesquisa (Processo 402134/20087).

\section{REFERÊNCIAS}

1. BELISARIO, A.; FORTI, E.; L. CORAZZA, L. First Report of Myrothecium verrucaria from Muskmelon Seeds. Plant Disease, Saint Paul, v. 83, n. 6, p. 589, 1999.

2. BHARATH, B. G.; LOKESH, S.; RAGHAVENDRA, V. B.; PRAKASH, H. S.; SHETTY, H. S. First report of the occurrence of Myrothecium verrucaria in watermelon seeds from India. Australasian Plant Disease Notes, Adelaide, v. 1, n. 1, p. 3-4, 2006. Disponível em: < http//: www.publish.csiro.au/journals/ apdn> Acesso em: 23 nov. 2014.

3. BHARATH, B. G.; LOKESH, S.; YASHOVARMA, B.; PRAKASH, H. S.; SHETTY, H. S. Seed-Borne Nature of Myrothecium roridum in Watermelon Seeds. Research Journal of Botany, New York, v. 5, n. 1, p. 63-64, 2010.

4. BRUTON, B. D. Podredumbre de carbón. In: ZITTER, T. A.; HOPKINS, D. L.; THOMAS, C. E. (Eds.). Plagas y enfermedades de las cucurbitáceas. Madrid: Ediciones Mundi-Prensa, 2004. p. 9-11.

5. CABRAL, C. S.; HENZ, G. P.; MOREIRA, A. J .A; REIS, A. New cucurbitaceous hosts of Myrothecium roridum in Amazonas State, Brazil. Tropical Plant Pathology, Brasília, v. 34, n. 6, p. 402-405, 2009. Disponível em: <http://www.scielo.br/scielo. phpscript=sci_arttextpid $>$ Acesso em: 12 nov. 2014.

6. DELWING, A. B.; FRANKE, L. B.; BARROS, I. B. I. Qualidade de sementes de acessos de melão crioulo (Cucumis melo L.). Revista Brasileira de Sementes, Londrina, v. 29, n. 2, p. 187-194, 2007. Disponível em: $<$ http://www.scielo.br/scielo.phpscript=sci_arttextpid $>$ Acesso em: 2 nov. 2014.

7. FISH, W. W.; BRUTON, B. D.; POPHAM, T. W. Cucurbit Host Range of Myrothecium roridum Isolated from Watermelon. American Journal of Plant Sciences, Irvine, v. 3, n. 3, p. 353-359, 2012. Disponível em: < http:/ www.SciRP.org/journal/ajps > Acesso em: 2 nov. 2014.

8. KUTI, J.; NG, T.J.; BEAN, G. A. Effect of inoculation with Myrothecium roridum Tode ex Fries on seed germination and early seedling growth of 12 cultivars of muskmelon (Cucumis melo). Cucurbit Genetics Cooperative Report, Madison, v. 8, n.1, p. 44-45, 1985.
9. LIMA, G. S. A.; OLIVEIRA, S. M. A.; BEZERRA NETO, E; MENEZES, M. Reação de cultivares de melão a isolados de Myrothecium roridum. Summa Phytopathologica, Botucatu, v. 23, n. 2, p. 135-139, 1997. Disponível em: < http://www.scielo.br/scielo. phppid > Acesso em: 11 nov. 2014.

10. MAGUIRE, J. D. Speed of germination-aid in selection and evaluation for seedling emergence and vigor. Crop Science, Madison, v. 2 , n. 2 , p. $176-177,1962$.

11. MENDES, F. F.; RAMALHO, M. A. P.; ABREU, A. F. B. de. Índice de seleção para escolha de populações segregantes do feijoeirocomum. Pesquisa Agropecuária Brasileira, Brasília, v. 44, n. 10, p. 1312-1318, 2009. Disponível em: < http://www.alice.cnptia. embrapa.br/bitstream > Acesso em: 15 nov. 2014.

12. NORONHA, M. A.; MICHEREFF, S. J.; XAVIER FILHA, M. S.; MOREIRA, P. A. A.; REIS, A.; SALES JUNIOR, R. Avaliação da resistência a Myrothecium roridum em genótipos de meloeiro. Horticultura Brasileira, Vitória da Conquista, v. 24, n. 4, p. 495498, 2006. Disponível em: < http://www.scielo.br/scielo.phppid > Acesso em: 5 nov. 2014.

13. NORONHA, M. A.; MICHEREFF, S. J.; MOREIRA, P. A. A.; XAVIER FILHA, M. S.; SALES JUNIOR, R.; MIZUBUTI, E. S. G. Variabilidade de isolados de Myrothecium roridum provenientes de meloeiro cultivado no Estado do Rio Grande do Norte. Tropical Plant Pathology, Viçosa, v. 33, n. 6, p. 432-438, 2008. Disponível em: < http://www.scielo.br/scielo. phpscript=sci_arttextpid $>$ Acesso em: 5 nov. 2014.

14. PARIS, H. S.; AMAR, Z.; LEV, E. Medieval emergence of sweet melons, Cucumis melo (Cucurbitaceae). Annals of Botany, Londres, v. 110, n. 1, p. 23-33, 2012. Disponível em: < http:// www.ncbi.nlm.nih.gov/pubmed > Acesso em: 5 nov. 2014.

15. R DEVELOPMENT CORE TEAM. R: A language and environment for statistical computing. $\mathrm{R}$ Foundation for Statistical Computing, Vienna, Austria. ISBN 3-900051-07-0, URL http:// www.R-project.org. (2016).

16. SCOTT, A. J.; KNOTT, M. A cluster analysis method for grouping means in the analysis of variance. Biometrics, Washington, v. 30, n. 3, p. 507-12, 1974.

17. SENHOR, R. F.; CÂMARA, M. P. S.; PRICHOA, L. F.; LIMA, M. B.; SALES JÚNIOR, R.; MICHEREFF, S. J. Influência do método de inoculação, intensidade do ferimento e idade do fruto na severidade da podridão-de-cratera em melão. Summa Phytopathologica, Botucatu, v. 34, n. 3, p. 232-237, 2008. Disponível em: $<$ http://www.scielo.br/scielo.php?script=sci_arttextpid $>$ Acesso em: 9 nov. 2014.

18. SILVA, D. M. W.; MENEZES, M.; OLIVEIRA, S. M. A.; PEREIRA, G. F. Ocorrência de Myrothecium roridum em melão em Mossoró, Rio Grande do Norte. Fitopatologia Brasileira, Brasília, v. 21, n. 4, p. 519, 1996.

19. SULTANA, N.; GHAFFAR, A. Pathogenesis and control of $M y$ rothecium spp., the cause of leaf spot on bitter gourd (Momordica charantia linn.). Pakystan Journal Botanic, Karachi, v. 41, n. 1, p. 429-433, 2009. 